\title{
The Efficiency of the Ventilated Gap of the Double-Skin Facade Systems Using Fire Crosscuts
}

\author{
Aleksandra Barabash ${ }^{1, *}$, Elizaveta Naumova ${ }^{1}$, Oksana Zhuvak $^{1}$, Darya Nemova ${ }^{1}$, and \\ Vyacheslav Olshevskiy ${ }^{1}$ \\ ${ }^{1}$ Peter the Great St. Petersburg Polytechnic University, 195251 Politechnicheskaya Str. 29, St. \\ Petersburg, Russia
}

\begin{abstract}
Double-skin facade is an excellent material for decoration of buildings. Despite the large number of advantages over other types of finishes, ventilated facades also have their drawbacks. In particular, a violation of installation conditions and fire safety regulations can lead to serious consequences. Innovative materials and structures in the field of fire safety are analyzed in this paper. The article deals with fire protection methods, special attention is given to the unit of fire crosscuts in the air gap of double-skin facade. Analysis of experimental data has revealed some drawbacks of this method and the necessity of design improvements.
\end{abstract}

\section{Introduction}

Recently, double-skin facades (DSF) are widely distributed due to their numerous advantages over traditional methods of facade finishing. The advantages are: energy efficiency, the flexibility of design decisions, noise protection and simplicity in installation at building's construction and reconstruction [1]. The structure of the curtain wall system is shown on (Fig. 1). The design is a steel frame connected with the insulant plate and facing panels. It is set on the outer part of the wall.

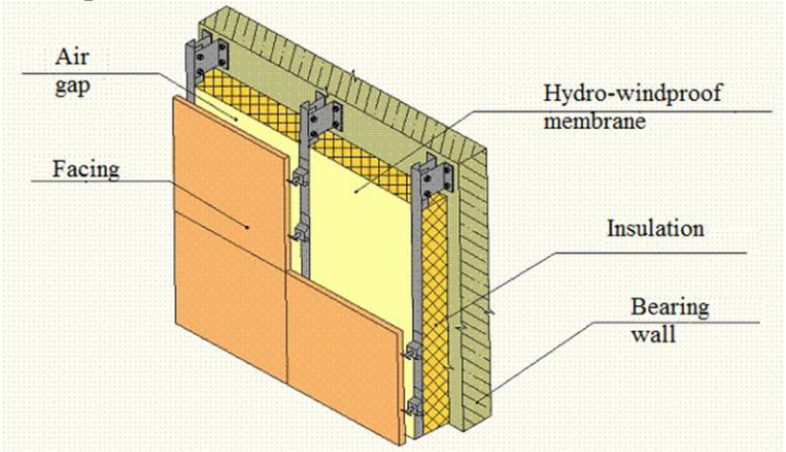

Fig. 1. The device of ventilated facade [2]

\footnotetext{
* Corresponding author: aleksandra17au@yandex.ru
} 
Ventilated facades are mostly used in decoration or renovation of urban, office and residential buildings [3]. According to HVAC system analysis involving the use of the simulation software Computational Fluid Dynamics (CFD), Autodesk Simulation CFD and Energy Plus ${ }^{\circledR}$, it is found that ventilated facade is an element of energy-efficient building. The construction keeps the fixed temperature inside the building regardless of the outside temperature changes that can significantly reduce the costs for air conditioning and heat [46]. The main difference of such facades is the presence of the air gap between the insulation and the facing protection material. The main purpose of the gap is to provide a thermal protection of the building, playing the role of the air buffer, reducing heat loss. One of the important properties is the removal of moisture: the condensation zone is shifted into the insulation layer which is bordered by a ventilated air interlayer [7]. In gap installation it is necessary to take into account technical characteristics and performance requirements of the building. If the preset thickness of the gap is excessive, the facade will buzz and whistle because of the impact of wind flow. Otherwise, in case of deficient air gap, the convective flow will be reduced, the moisture removal will be impossible; the insulation will damp and collapse eventually. In this situation the function of the air gap is reduced to zero.

For obtaining the qualitative and durable system it is necessary to comply with all installation and exploitation requirements and use high-quality materials only. Thus, the main problems of hinged ventilated facade systems are [8]:

- Calculating the necessary ventilated gap

- Choice of high-quality materials

- Qualitative installation execution

- Provision of the required heat transfer resistance

- Fire safety

The demand for these systems are explained by their functionality: DSF systems give not only an impressive architectural appearance to building, but also carry out the thermal protection functions and contribute to the normalization of the building's heat and humidity mode which achieved due to the design of these systems [8].

Fire safety is the most important parameter which is worth to take into account when installing the DSF. Basic requirements for the facade systems are established by The Federal Law "Technical Regulations on Fire Safety Requirements" [9]. The various aspects of fire safety of materials in the construction of facade systems are described in [10-12], which contain the classification of flammable materials on the smoke-forming ability and the toxicity of combustion products.

The most dangerous area of ventilated facade is a metal frame. It is responsible for ensuring the integrity and stability of the whole structure. Therefore, the use of fusible metals in the construction of the frame are not recommended. Otherwise, at the fire, parts of the facade will break down and fall, injuring passers-by and damaging nearby facilities. Thus, the most reliable are steel frames [13].

The composition of the facade also includes waterproof film which can easily catch fire in case of violation of assemble and exploitation conditions. No less common cause of fires is the use of low-quality or flammable cladding materials. In particular, the use of aluminum composite panels (ACP) was the cause of the rapid spread of fire on the facade of the building Address Downtown, Dubai; in high-rise building "Transport Tower", Astana; in high-rise building complex "Grozny City", Grozny.

In order to protect the structure during a fire, the following measures are used:

- The use of high-quality, fire-resistant materials, the relevant The Federal Law N 123

- $\quad$ The use of fire box 
- The use of fire crosscuts

One of the measures of fire safety, in addition to the use of non-flammable materials, is installing the fire-protective boxes. The fire-protective box is a metal structure on the perimeter of window and door openings, attached to the wall by anchors. It can be done as a single structure or as a composite, interconnected by the metal ware. The space between the metal elements is filled with heat-resistant mineral wool. It does not allow the flame to penetrate into the facade. However, this system is not effective in conditions where the fire source is located outside the premise.

Therefore, fire crosscuts are set with definite step, spanning the whole thickness of the air gap. In case of fire, they prevent the spread of combustion of windproof membrane and falling of burning droplets film out of the gap [14], as well as the spread of flammable gases by perimeter wall.

Fire crosscut is a metal plate (solid or perforated) made of sheet steel with a minimum thickness of $0.6 \mathrm{~mm}$ and at a distance of not less than $6 \mathrm{~m}$ from each other. Since crosscuts should fit snugly to the facade when installed, function of the gap is reduced to zero. Therefore, perforation in a crosscut is performed in order not to disturb the movement of the air flows. The degree of punching is defined by calculations. According to [9] fire crosscuts can be attributed to a fire barrier, but the specific design requirements are only for structures that prevent the spread of fire from one room to another, and therefore are not covered.

(Fig. 2-3) presents assemblies of fire crosscuts by Kraspan and Sial systems.

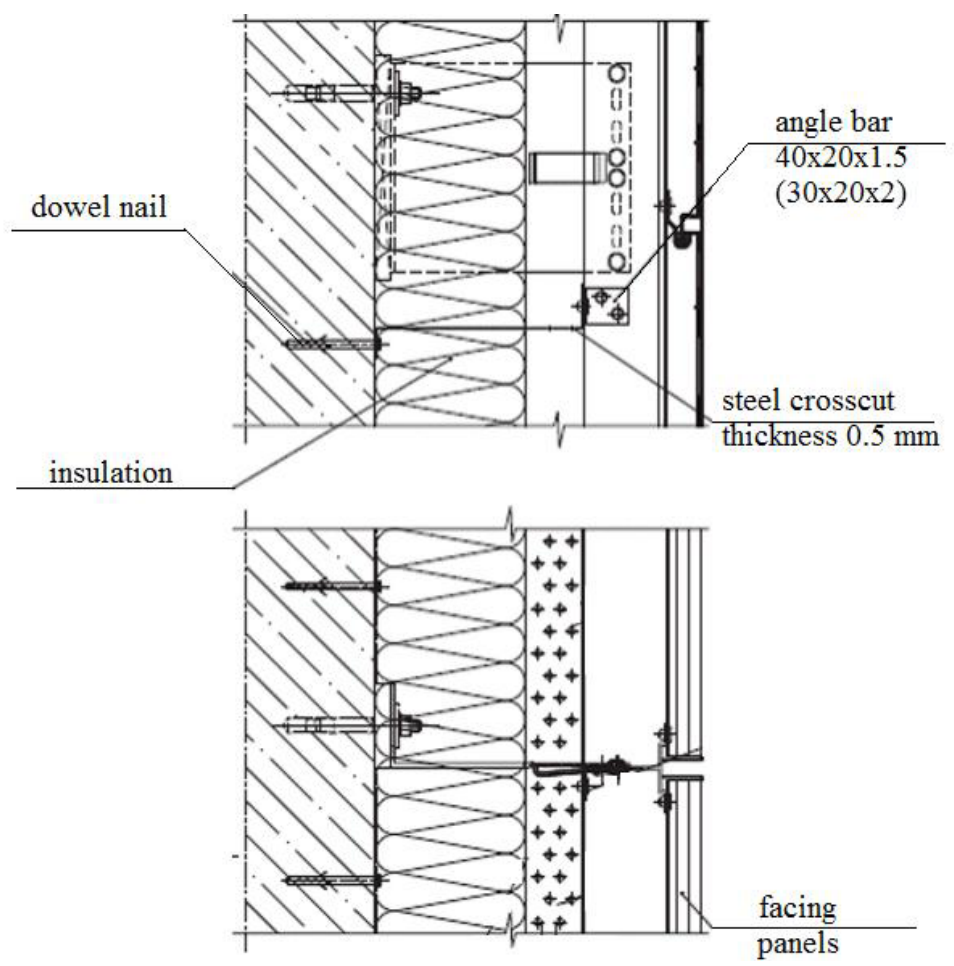

Fig. 2. An embodiment of the ventilated facade with perforated crosscuts [15] 


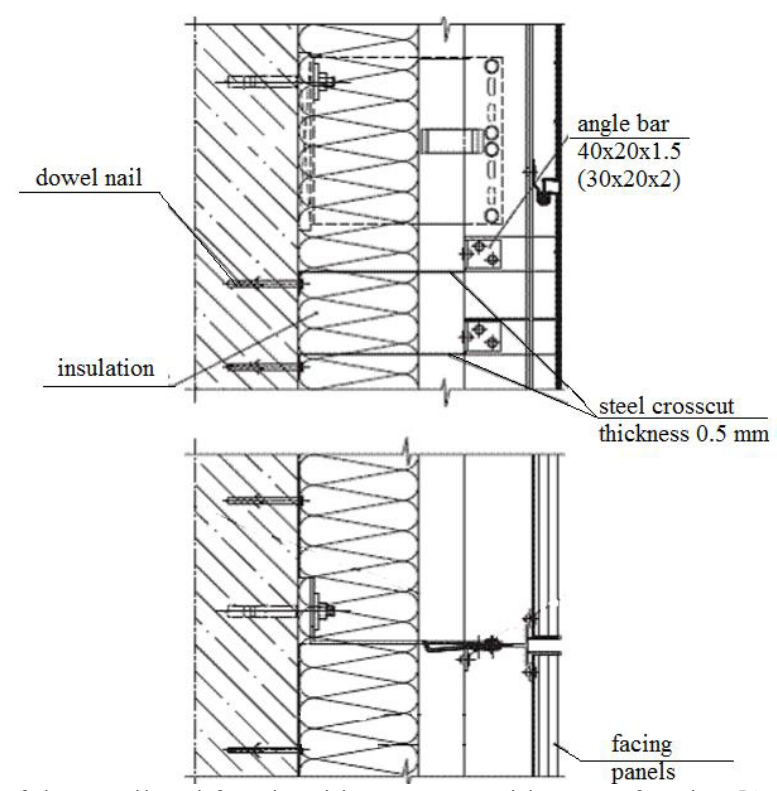

Fig. 3. An embodiment of the ventilated facade with crosscuts without perforation [15]

In the Kraspan system the perforated metal crosscut completely covers the gap. In the Sial system it spans gap partially, until the edge of the vertical profile. Also, there is embodiment of crosscut performance consisting of two continuous sheets, raised in height with overlap.

\section{Publications review}

Research of a number of famous scientists is devoted to this theme [16-20, 34-35]. In article [21] the importance of the use of fire crosscuts to ensure fire safety facilities is considered, as well as the need for measures to prevent fire and falling of combustion products.

Great attention should be paid to the material of crosscuts, as it must meet all the requirements of fire safety, the most important of which is do not let the fire spread across the facade.

A.D. Zhukov, A.V. Chugunkov set task to produce a material for fire crosscuts homogeneous structure [22]. The experience of products' bench manufacturing of flexible membranes is taken into account. These membranes allow to adjust the excess tension, and the material retains its structure with minimal variation in density. The consequence of this method is application of aerated concrete as expanding fire crosscuts. In this case, aerated concrete poured into the mould is sandwiched between sheets of insulation and formwork. The mixture distends, forming stress condition and cellular mixture fills all voids and leakages, thus relaxing own excess tensions [22].

If the building is not equipped with fire crosscuts, it belongs to a class $\mathrm{K} 3$ fire danger according to [23].

In [24] authors make demands to the material, targeted for a product with desired properties (primarily low thermal conductivity) and maintaining these properties over time in specific operating conditions. In this case two kinds of constraints are taken into account: safety of material in terms of fire impacts and minimizing negative impacts on the environment. 
Geir Jenssen leads in his article the European and American testing standards of ventilated facades on the impact of the fire. In particular, comparative evaluation of the use of perforated and solid cut-offs according to European standard tests E2912-13 is performed [25]. David Crowder has reviewed the methods of experiments based on Fourier transform (FTIR) to analyze the effect of toxic gases on the rate of spread of a fire. The tests have been produced in special flue boxes BS EN ISO 5659 [26].

The conclusion based on reviewed papers is that fire-fighting crosscuts are the best way of protection of the facade against the spread of flame, however, it is necessary to identify how this system will affect the functionality of the DSF.

Purpose: to assess the impact of fire crosscuts on the efficiency of a ventilated gap.

Objectives:

- To conduct a theoretical assessment of the impact of fire crosscuts on the air flow in the ventilated fence of DSF;

- To make the experiment on a physical model of the ventilated gap in the laboratory

\section{Advantages of double-skin facades}

Ventilated facades are increasingly used by builders. The removal of atmospheric moisture and condensate from the building envelope happens due to the air gap between the insulation and facade cladding in ventilated facade of the building [27].

Specific points of ventilated facade:

1. This facade can significantly reduce the thickness of the bearing wall, which leads not only to direct savings of wall materials, but also allows to soften the requirements to the bearing capacity of the Foundation [28];

2. With the right setup of the facade the danger of moisture condensation inside walls of elements is eliminated $[28,29]$;

3. In the event of a catastrophic destruction of the insulating layer the functionality of the facade can be quite easily recovered by pouring the resulting cavity with airpolymerizing foam composition or filling lightweight backfilling — expanded clay aggregate or foamed glass [30, 31];

4. For facade masonry is not necessary to use "warm" masonry mortars [32];

5. As the material for the top layer of the facade could be used a cost-effective ceramic and clinker bricks of "American type" [28].

Advantages:

1. High workability: preparation of a bearing wall is almost not required; all components have a high degree of prefabrication;

2. High speed of installation;

3. The absence of "wet" processes;

4. Installation of systems of ventilated facades is simple, but requires qualification and training of workers;

5. The device does not require scaffolding; installation can be carried out with cradles;

6. Facing the elements if necessary can be customized by size directly on the site [32];

7. The possibility of carrying out installation work at any time of the year;

8.Design features allowing to increase the service life of building elements, the estimated lifetime can reach 50 - 100 years;

9. Low operating costs;

10. A wide range of coating materials allows to realize almost any design decision [27]. 


\section{An experiment on a physical model}

In the experiment, the perforated fire crosscuts shown on (Fig.4) block most of the ventilated gap.

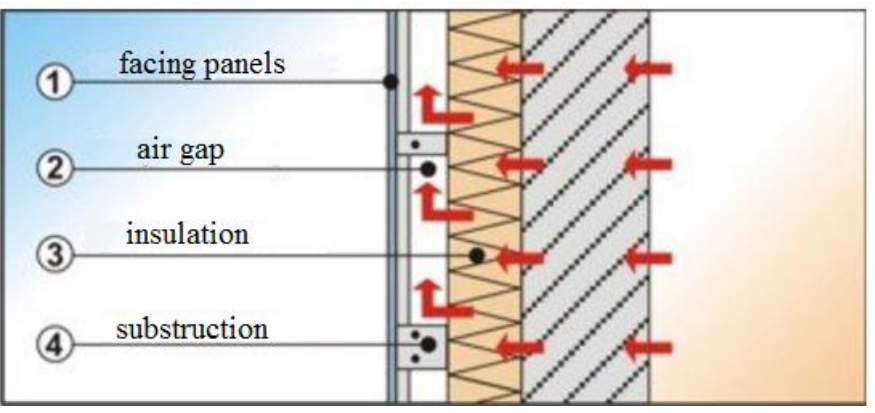

Fig. 4. Scheme of a double-skin facade [33]

There are installations in which the air flow velocity changings in the gap can be studied, as well as temperature, depending on the width of the air gap under the influence of the crosscut and without it.

The physical model of a vertical ventilated layer (Fig.5). is an installation $2040 \mathrm{~mm}$ in height, $600 \mathrm{~mm}$ in width, there are two faces bounding the air gap and simulating the facing layer (non-heated) and the wall of the building. One of the faces of the installation is heated and fixed, the second face, simulating the facing layer, is unheated and can move free, creating a different air gap width $\mathrm{h}$ in the range $20-300 \mathrm{~mm}$. The edge which imitates the facing layer (unheated), consists of sheets $300 \mathrm{~mm}$ high, separated by $5 \mathrm{~mm}$ gaps, imitating rustication. There is also an opportunity providing to control access of air from the bottom of the channel. Over the entire height of the unit a heating element is located which allows to supply the heat for heating the motionless face.
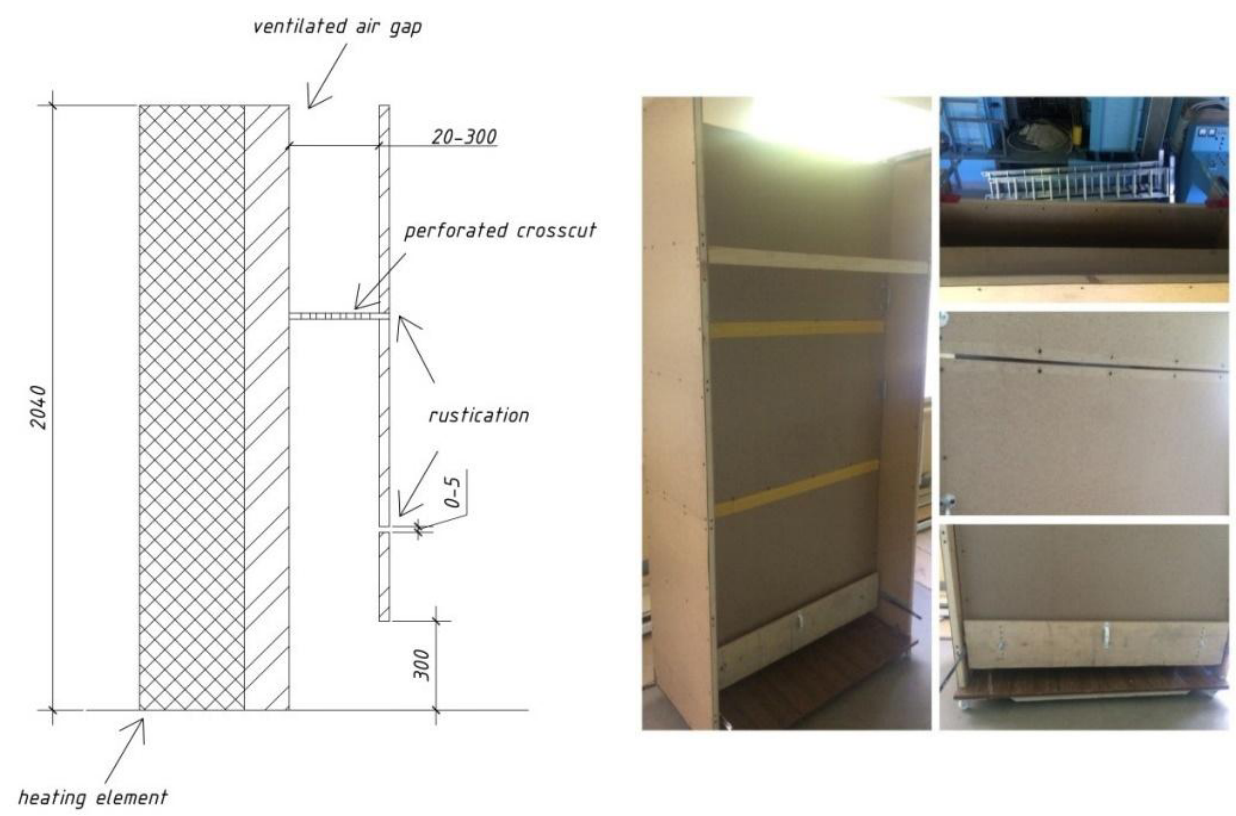

Fig. 5. Installation for physical experiments [8] 


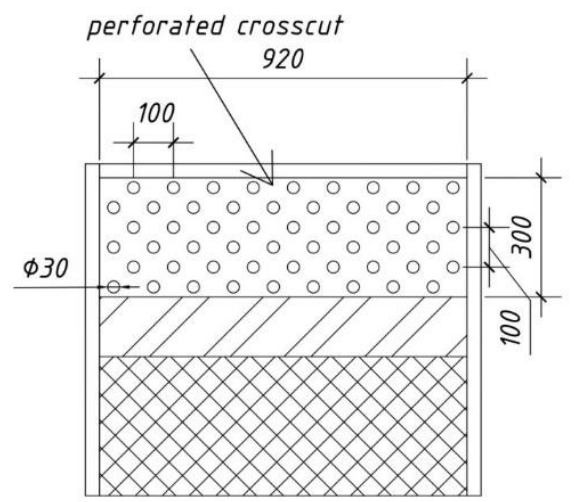

Fig. 6. Top view of the installation.

Thus, the installation (Fig.6). allows measurements by adjusting the geometrical parameters of the air gap.

A series of experiments have been carried out under the following sizes and installation configurations on a physical model to confirm the theoretical calculations and the numerical experiment and also studying the effect of crosscuts on the role of the air gap and air access:

1st case: the crosscut is not used, free flow of air in the gap is organized

2nd case: the perforated crosscut is across the width of the gap

In both cases, the width of the air gap was variable and ranged from 20 to $300 \mathrm{~mm}$. Height of the air gap was constant and amounted to $2040 \mathrm{~mm}$.

Before a series of experiments, the temperature was measured in the laboratory, which amounted to $293 \mathrm{~K}$. During the experiment, in both cases, the average speed and the temperature of the air flow in the channel at each width of the air gap was measured using a hot-wire anemometer.

The air velocity varied from $0 \mathrm{~m} / \mathrm{s}$ to $0.7 \mathrm{~m} / \mathrm{s}$, the temperature varied from $296.8 \mathrm{~K}$ to $309.7 \mathrm{~K}$.

In the case of use of fire crosscut the imitation (Fig.7). was taken, which represented a piece of chipboard the size of $920 \times 300 \times 5 \mathrm{~mm}$, with $13 \%$ degree of perforation (the hole diameter is $30 \mathrm{~mm}$, the interval between them is $100 \mathrm{~mm}$ ).

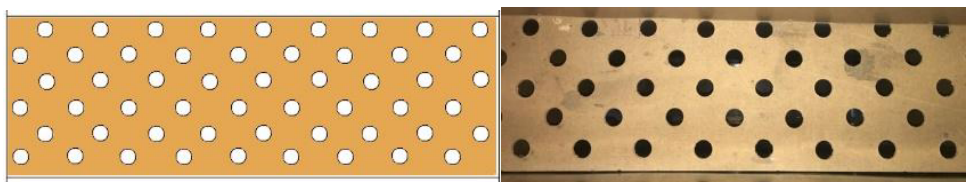

Fig. 7. The view of the crosscut from the top.

Processing of experimental data was performed for two series of experiments. $\mathrm{L} / \mathrm{h}$ and $\varphi$ were used as the variables.

\section{The calculated dependencies}

1. The General formula for average speed:

$$
v=\varphi \sqrt{1-\frac{T_{C}}{T_{h}}} \sqrt{2 g L}[8]
$$


where:

$$
\varphi=\frac{1}{\sqrt{1+\lambda \frac{L}{h}+\zeta}}-\text { speed coefficient }
$$

$\lambda$ - the coefficient of hydraulic friction,

$\zeta$ - coefficient of local pressure loss,

$L$ - the height of a ventilated gap,

$\mathrm{h}$ - the width of the gap,

$T_{c}$ - the room temperature in Kelvin,

$T_{h}$ - the temperature of the heating element in Kelvin;

2. With crosscuts $(v \approx 0.1)$ :

$$
v=\varphi \sqrt{1-\frac{T_{C}}{T_{h}}} \sqrt{2 g L} \rightarrow \varphi \rightarrow+0
$$

The installation of crosscuts increases the channel resistance, reducing $\varphi$ to zero.

$$
\begin{gathered}
\varphi=\frac{1}{\sqrt{1+\frac{\lambda L}{h}}} \\
1+\lambda \frac{1}{\mathrm{~h}}=\frac{1}{\varphi^{2}} \\
\varphi_{\mathrm{p}}=\frac{1}{\sqrt{1+\frac{\lambda L}{h}+\zeta_{p}}} \\
\rightarrow \zeta_{p}=\frac{1}{\varphi_{p}^{2}}-\frac{1}{\varphi^{2}} \\
\sqrt{1-\frac{T_{c}}{T_{h}} \sqrt{2 g L}}
\end{gathered}
$$

The maximum coefficient of local pressure loss of crosscuts was calculated when flow velocity was $0.1 \mathrm{~m} / \mathrm{s}: \zeta_{p}=566.67$

The graph of speed dependence $\varphi$ from the ratio of the height of the ventilated gap L to its width $\mathrm{h}$ is shown on (Fig. 8).

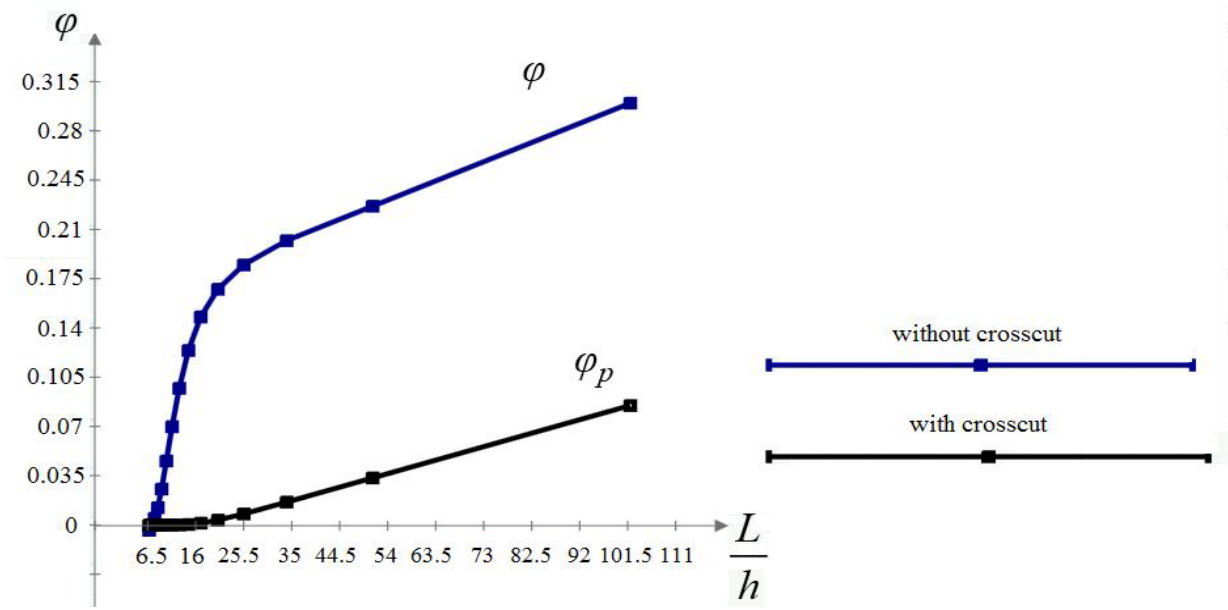

Fig. 8. A graph of dependence $\varphi$ from $\mathrm{L} / \mathrm{h}$ 


\section{Conclusions}

During the carried-out tests and calculated results, it was found that while using the crosscuts (even perforated), the air gap's role is reduced to zero, because the facade stops working as ventilated. With a relatively small gap size of $60 \mathrm{~mm}$ the air flow velocity drops to zero, air circulation with further increase of channel doesn't occur. On the one hand, this means that the crosscut actually works as a means of preventing the spread of hot and flammable vapors along the facade. But on the other hand, it interferes with the normal air convection inside the facade. It can be concluded that the rational solution is the use of noncombustible materials or installation the system of automatic "ejection" of crosscuts in case of fire. It could be implemented as follows: in the design of the facades to provide thermal anemometers, which will register a temperature increase above a certain limit. In case of fire the signal from the anemometer is transmitted to a remote control system of crosscuts and they fall across the entire air gap. The scheme of the device is shown in (Figs. 9-10).

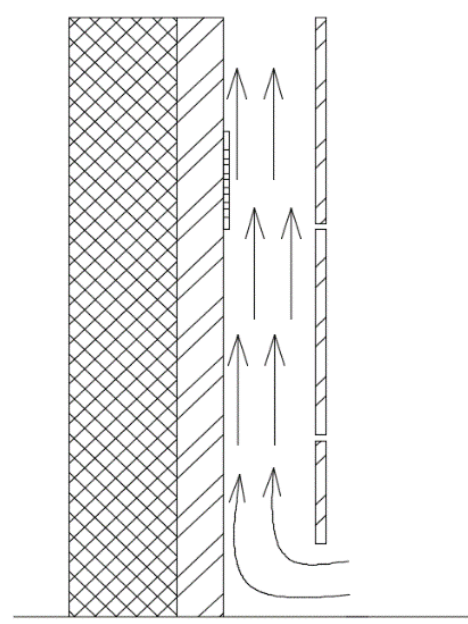

Fig. 9. Normal position of the crosscut - along the facade

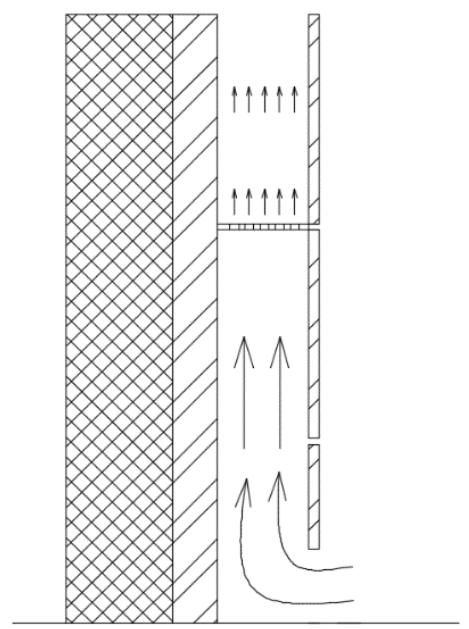

Fig. 10. Case of fire - crosscut closes air gap

\section{References}

1. C. Suarez, P. Joubert, J. L. Molina, F. J. Sanchez, Ener. and Build., 43, 3696-3703 (2011)

2. Information on http://vfasade.blogspot.ru/2013/06/no-fire.html

3. D.V. Nemova, Mag. of Civil Eng., 5, 7-11 (2010) (rus)

4. B. Gaujena, A. Borodinecs, J. Zemitis, A. Prozuments, IOP Conference Series: Materials Science and Engineering, 96 (1) (2015)

5. N. Harmati, Z. Jakšić, N. Vatin, Proc. Eng., 117 (1), 791-799 (2015)

A. Borodinecs, J. Zemitis, A. Prozuments, Proceedings of World Renewable Energy Forum (WREF 2012) 4181-4186 (2012)

6. A.D. Zhukov, SCE, 1, 1-15 (2012) (rus)

7. D.V. Nemova, PhD Tesis: 05.23.16, Peter the Great St.-Petersburg Polytechnic University, Saint-Petersburg, 18 (2015) (rus)

8. The Federal Law N 123 (Moscow, 2008) (rus) 
9. National Standard of Russian Federation 30244-94 (Moscow, 1995)

10. National Standard of Russian Federation 30402-9 (Moscow, 1996)

11. National Standard of Russian Federation 12.1.044-89 ( Moscow ,1996)

12. I.R. Khasanov, I.S. Molchadsky, K.N. Goltsov, AV. Pestritsky, FS, 5 (2006) (rus)

13. V. N. Vorobev, (Vladivostok, 2012) (rus)

14. Information on http://vfasade.blogspot.ru/2013/07/uzel-ventfasad.html

15. S.A. Isaev, N.I. Vatin, S.V. Guvernyuk, V.G. Gagarin, B.I. Basok, Y.V. Zhukova, High Temp., 53 (6), 873-876 (2015)

16. G.I. Grinfeldi, A.S. Gorshkov, N.I. Vatin, Mat. Res., 941-944, 786-799 (2014)

17. N.I. Vatin, J. Havula, L. Martikainen, A.S. Sinelnikov, A.V. Orlova, S.V. Salamakhin, Adv. Mat. Res., 945-949, 1211-1215 (2014)

18. M.R. Petrichenko, D.W. Serow, J. NPCS. 17 (3), 336-339 (2014).

19. Nefedova, J. Bykova, S. Kosov, M. Petrichenko, Proc. Eng., 117 (1), 1102-1111 (2015)

20. I.A. Lobaev, A.J. Bazilevich, A.O. Andreev, Materialy dvenadcatoj nauchnotehnicheskoj konferencii «Sistemy bezopasnosti», 47 - 249 (Moscow, 2003.) (rus)

21. A.D. Zhukov, A.V. Chugunkov, Proc. MSUCE, 5, 128-132 (2012) (rus)

22. National Standard of Russian Federation 31252-2003 (Moscow, 2003) (rus)

23. B.M. Rumyantsev, A.D. Zhukov, T.V. Smirnova, 4 (35), 3 (Volgograd, 2014) (rus)

24. G. Jensen, Proc. of matec web of conf., 9, 1-11 (2013)

25. D. Crowder, BRE Trust Review 2012, 46-47 (2013)

26. A.E. Kiryudcheva, V.V. Shishkina, Const. of Un. Build. and Struct., 4 (31), 248-262 (2015) (rus)

27. E. Cykanovski, V. Gagarin, A. Granovski, M. Pavlova, Build. Tech., 6, 28-33 (2002) (rus)

28. Centralny nauchno-issledovatelski $i$ proektny institut jilyh $i$ obscestvennyh zdanii (CNIIEP zhilishha), (Pravitelstvo Moskvy, Moskomarhitektura, 2002), Dmitriev, Ensber., 6 (2001) (rus)

29. A.S. Gorshkov, Mag. of Civil Eng., 1, 9-13 (2010) (rus)

30. M.A. Platonova, N.I. Vatin, D.V. Nemova, S.A. Matoshkina, D. Iotti, I. Togo, Const. of Un. Build. and Struct., 4 (19) ,83-95 (2014) (rus)

31. Information on http://pfkmsk.ru/

32. M. Penić, N. Vatin, V. Murgul, App. Mech. and Mat., 680, 534-538 (2014)

33. A. Gorshkov, V. Murgul, O. Oliynyk, MATEC Web of Conf., 53 (art. no. 01045, 2016) 